\title{
Attitudes, Perceptions, and On-Farm Self-Reported Practices of Shrimp Farmers' towards Adoption of Good Aquaculture Practices (GAP) in Thailand
}

\author{
Chitrlada Booncharoen (D) and Anil Kumar Anal *(D) \\ Department of Food, Agriculture and Bioresources, Asian Institute of Technology, \\ Klong Luang 12120, Pathum Thani, Thailand; st118388@ait.ac.th \\ * Correspondence: anilkumar@ait.ac.th
}

Citation: Booncharoen, C.; Anal, A.K. Attitudes, Perceptions, and On-Farm Self-Reported Practices of Shrimp Farmers' towards Adoption of Good Aquaculture Practices (GAP) in Thailand. Sustainability 2021, 13, 5194. https://doi.org/10.3390/su13095194

Academic Editor: Piotr Prus

Received: 5 April 2021

Accepted: 5 May 2021

Published: 6 May 2021

Publisher's Note: MDPI stays neutral with regard to jurisdictional claims in published maps and institutional affiliations.

Copyright: (c) 2021 by the authors. Licensee MDPI, Basel, Switzerland. This article is an open access article distributed under the terms and conditions of the Creative Commons Attribution (CC BY) license (https:/ / creativecommons.org/licenses/by/ $4.0 /)$.
Abstract: The purpose of this research is to evaluate the perceptions and attitudes relating to Good Aquaculture Practices (GAP) in compliance held by a subgroup of Thai GAP certified shrimp farmers based on a structured questionnaire and in-depth interviews. Different levels of farmers' experiences with the method of farming resulted in significant differences in perspective and attitude in some domains studied, especially environmental sustainability and constraints to GAP production. Moreover, all farmers were willing to adopt GAP in order to create a safer certified farm, including reducing chemical use and reporting outbreaks of disease. Their main concerns surrounded the expenses required to change practices and farm safety certification to the shrimp farmers improvement, market volatility, and price fluctuations. It was evident that the important issues remain regarding GAP cost. The outcomes of this study will help farmers to understand the requirements towards safer and sustainable production and support policy developers in development of policies, strategies, and programs to encourage participation in GAP certification.

Keywords: Good Aquaculture Practices (GAP); farmers' perspective; farmers' attitudes; certification; shrimp farming

\section{Introduction}

In recent years, consumers have shown increasing concern with the health benefits, food safety, and quality of their food products. This comes in parallel with higher literacy rates and education levels of consumers. The recurrences of food-borne illness and diseases along with the current global COVID-19 pandemic have raised awareness of food safety issues among all the stakeholders, including producers, processors, retailers, and consumers. This has not only reduced consumers' confidence in food safety but also raised more significant concerns regarding the sustainability of the food industry and trade [1-3]. Production sustainability, environmental responsiveness, and animal welfare are core concerns globally, reflected in the United Nations Sustainable Development Goals (UN SDGs). This translates into a willingness to pay higher prices for sustainably sourced 'premium' goods. Corsin et al. [4] identified that retail marketing influences what consumers are willing to pay as much as what they want to buy. This increasing focus on food safety and sustainability through the entire production chain makes possible a drive towards the emergence of a new market of safely produced ethical food products [5-7]. It is going to be essential to offer evidence about food safety control systems, such as Good Agricultural Practices (GAP), Good Manufacturing Processes (GMP), etc. to retailers and consumers to increase confidence levels. In the domestic markets of Thailand, retail stores have been considered as the most important influencers for the adoption of such practices by producers $[7,8]$.

The "Theory of Planned Behavior (TPB)" has generally been used theory in social and behavioral science including on the food safety knowledge, attitude, and practices (KAP) of 
food handlers [9]. This provides a systematic way of understanding behaviors by specifying relations among variables. A few reports have recently been published on the practices of farmers at the primary production level, such as dairy producers for quality control in Canada [10], the lettuce farmers engaged in on-farm food safety practices in Iran [9], and the safety and quality related behavior of swine farming in China [11]. The KAP, a quantitative survey tool, has similarly extensively been employed in various health-related studies, relating to sanitation, personal hygiene, and other disease preventive measures. The food safety measures taken initially at farm level are necessary barricade to prevent the occurrence of food safety issues, and thus to ensure the safer food products. However, there are limited studies on-farm level food safety in aquaculture. Recent advances in aquaculture technology and rising demand for global shrimp farming are very important for the economy. Since the 1970s, the favored species has been Penaeus monodon, also called the giant tiger prawn or black tiger shrimp. In 1999, the white leg shrimp (Litopenaeus vannamei, formerly Penaeus vannamei), also known as the Pacific white shrimp, was also introduced [12].

At present, Thailand is a significantly important contributor to aquaculture production for both domestic and global markets, mostly for Penaeus vannamei. The total production of shrimp was about 298,343 tons in 2018, of which Penaeus vannamei accounted for 259,966 tons, roughly $87 \%$ of all marine shrimp gained from aquaculture. The United States of America (USA), Japan, European Union (EU), and Canada are the largest markets for P. vannamei exports, amounting to a combined 146,710 tons, at a value of around USD 1.42 billion [13]. The aquaculture sector is looking for efficient tools to reassure consumers and retail buyers due to progressively stricter regulations concerning product safety and production methods. The ever-growing demand and rapid growth in the industry have led to environmental and food safety problems. The resulting public concern has led many buyers to ask for product quality guarantees. This, in turn, has influenced the increase in requests for GAP certification [14].

Good Agricultural Practices (GAP) covers the processes of producing crops (e.g., fruits, vegetables, and grains) and livestock (e.g., meat, eggs, milk, leather, and wool). A specific type of GAP, referred to as Good Aquaculture Practices, covers specific aquafarming concerns for products including fish, crustaceans, mollusks, aquatic plants, and algae. The practice standards relating to the quality, sustainability, and food safety characteristics of both domestically grown and imported agricultural products. GAP extends the concept of sustainability beyond that which farmers have traditionally focused on, from economic to environmental and food safety concerns [15]. Thailand's National Policy is highly concerned with public health and especially related to food safety and overseen by the National Bureau of Agricultural Commodity and Food Standards (ACFS). An attempt has been made to direct small-scale farmers to improve on-farm operations, with the goal of improving food safety and controlling food processing throughout the food chain. GAP has widespread global acceptance as a set of standards contributing to the safe and sustainable cultivation of marine food products. GAP is necessary for the sector to produce food products which comply with food laws and regulations.

In Thailand, the main government agency responsible for aquaculture standards training, auditing, and certifying is the Department of Fisheries (DOF) under the Ministry of Agriculture and Cooperatives (MOAC). Products and production systems are certified in accordance with GAP as international standards to support the DOF policy of enhancing aquaculture capabilities. Standard certifications are divided into two types as follow:

(1) "General standards" or "voluntary standards" for the benefit of production development to meet international standards rather than for enforcement.

(2) "Mandatory standards" are those under Ministerial Regulations that require compliance for agricultural products for reasons of consumer health protection or are necessary for the economy. Exports are required to follow mandatory standards.

The DOF has implemented general or voluntary standards for the GAP certification program to promote hygiene, food safety, and the prevention of chemical residues. The 
GAP standard for shrimp farming was first certified in 2003 by the DOF [16]. In 2009, Good Aquaculture Practices for marine shrimp farm, or GAP-7401 standard, was developed by the ACFS to correspond to demands consistent with international guidelines. The number of GAP certified shrimp farms in Thailand was only 9111 out of a total of 12,814 registrant farms [17]. The reason for having lower GAP certified farmers is still unclear. The lack of farmers' knowledge and awareness towards the adoption and benefits of GAP could be one reason. Increasing the understanding on attitudes of shrimp farmers in the region may shed light on the causes of slow adoption and highlight strategies to improve GAP standards implementation. None of the research has yet been conducted towards finding the stakeholders' perceptions, knowledge, and attitudes for the GAP in aquaculture. This research thus aims to investigate the farmers' perceptions and attitudes on the adoption of Good Aquaculture Practices (GAP) in shrimp farming for future growth and trade.

\section{Materials and Methods}

\subsection{Study Design}

The cross-sectional KAP study was conducted to identify the issues affecting GAP adoption in the Thai shrimp farming industry [18]. The study area included three provinces in the eastern region of Thailand, with 2889 GAP shrimp certified farms, accounting for $31.71 \%$ of the total GAP shrimp farms in the country (9111 farms). The selected provinces were Chachoengsao (1180 farms), Chanthaburi (911 farms), and Trat (408 farms) [13]. The estimate of the sample size was analyzed following the formula developed by Yamane [19]. The overall data set was comprised of 508 GAP farms from districts of Chachoengsao (Bangkhla, Muang, Khlong- Khuean), Chanthaburi (Laem-Sing, Tha-Mai, Na-Yai-Am), and Trat (Muang). All of the respondents were registered and certified with GAP standards by the DOF.

\subsection{Data Collection, Survey Methods, Tools, and Analysis}

The exploratory survey was conducted to obtain the information on actual farms in selected province of Thailand. The region and provinces were primarily selected based on having the highest density of GAP certified farms, followed by the districts in the region having a higher number of GAP standards shrimp farms. The primary data was collected by interviewing (face-to-face) the farmers with structured questionnaires between January and September 2019. Secondary data on lists of GAP certified farmers were provided by DOF, Thailand. The questionnaires were validated by the experts from the Department of Fisheries, Thailand. The farmers were categorized into three groups based on the year of GAP adoption. Those who had adopted GAP farming for less than three years (newadopters) accounted for $20.5 \%$, whereas mid-adopters (3-6 years) accounted for $36.2 \%$ of the sample. About $43.3 \%$ of the farmers (old- adopters) were found adopted GAP for more than 6 years. Similar systems to classify groups of adopters have been used in previous studies $[20,21]$. The Statistical Package for the Social Sciences (SPSS) software Version 23 was used for the descriptive statistical analysis. Mean values obtained in different groups for metric variables were compared by one way ANOVA. Chi-square was generated for the comparison of frequencies of categorical data. Farmers' perception and attitudes were examined by scoring a series of statements on a one to five Likert scale (i.e., ranking in terms of "strongly disagree", "disagree", "undecided", "agree", and "strongly agree"). Then, Weighted Average Index (WAI) was used to rank the three groups of farmers' perceptions and attitudes based on the GAP standards [22,23]. The calculation formula of WAI is as follows:

$$
W A I=\sum \frac{S i F i}{N}
$$

where WAI represents the weighted average index $(0 \leq W A I \leq 1)$, Si means the scale value assigned based on the farmers' response, $F i$ denotes the frequency of farmer responses, and $\mathrm{N}$ means the total number of farmer responses. The perception level was kept from 0 to 
1 namely, $0=$ very weak, $0.25=$ weak, $0.5=$ medium, $0.75=$ strong, $1=$ very strong. The formula for calculating perception level is as follows:

$$
W A I=\frac{\left(1.00 \times f_{1}+0.75 \times f_{2}+0.5 \times f_{3}+0.25 \times f_{4}+0 \times f_{5}\right)}{N}
$$

where $f_{1}$ is the frequency of respondents of first scale choice (scale $5=$ strongly agree); $f_{2}$ is the frequency of respondents of second scale choice (scale $4=$ agree); $f_{3}$ is the frequency of respondents of third scale choice (scale $3=$ undecided); $f_{4}$ is the frequency of respondents of fourth scale choice (scale $2=$ disagree); $f_{5}$ is the frequency of respondents of fifth scale choice (scale $1=$ strongly disagree). The level of below 0.21 is considered as "strongly disagree", $0.21-0.4$ as "disagree", $0.41-0.6$ as "undecided", $0.61-0.8$ as "agree", and 0.81-1 as "strongly agree".

\section{Results and Discussions}

\subsection{Descriptive Statistics and Comparison of Characteristics between Adopter Groups}

Table 1 shows the demographic characteristics of adopter groups, including gender, age, education, and year of farming experience. From 508 total respondents, 104 were "new- adopters," 184 were "mid-adopters," and 220 were "old-adopters." Most female respondents $(51.4 \%)$ were old-adopters, followed by mid-adopters and new-adopters. Males comprised $48.6 \%$ of old-adopters, followed by mid-adopters and new-adopters. There were no significant gender differences between adopters. Van Bac et al. [24] also revealed that there is no impact of gender on the likelihood of implementing agricultural technologies. In contrast, Ngokkuen and Grote [25] reported that the farmers' gender revealed a positive effect and was considerably concerned with Geographical Indications (GI) certification and adoption. Similarly, Nkamleu and Manyong [26] also found that gender plays a vital and positive impact on the implementation of agroforestry in Cameroon. Age was found to play a significant role in adoption. The mean age among adopters was 47 years. The group of farmers who were between $41-50$ years accounted for $31.70 \%$ of the respondents, those less than 40 years old made up $31.09 \%$ of respondents, and approximately $37.21 \%$ of the respondents were older than 51 years. In this study, new-adopters were usually the younger ones and followed some of the current practices $[20,21]$. The noteworthy influence of age on the choice to become certified was also identified by Ruben and Fort [27], whereas Kersting and Wollni [28] found negative stimulus of the age differences for the choice to implement agricultural changes. In terms of formal education, less than half of the respondents $(41.34 \%)$ had completed secondary school. About $32.88 \%$ of respondents had a bachelor's degree or diploma, while $8.46 \%$ of respondents had earned higher qualifications. There was no significant difference $(p<0.05)$ between adopters concerning the variations in education levels. Similarly, Läpple and Van Rensburg [20] reported that there was no difference in disparity in education level between the adopter groups.

The education level of farmers did not impact the decision to change to VietGAP farming from traditional farming in Vietnam [24]. However, Muddassir et al. [29] noticed that educated farmers tend to be more likely to have positive perceptions regarding new production procedures, compared to less educated farmers. The mean duration of farming experience among adopters was 24 years. The mean experience of new-adopters and mid-adopters was 19 and 22 years, respectively, compared to 28 years for old-adopters. The F-test shows the statistical difference in the farming experience among adopters $(p<0.001)$. The result confirmed that old-adopters had more experiences than either new or midadopters. This affirms the general conviction that more experienced farmers are more likely to be early adopters of new practices [21]. The results showed that GAP adopters varied by age as well as farmers' experiences. A significant difference among farming experiences in GAP adopters was also found. The older GAP adopters had higher experience in farming. Thus, it can be concluded that differences in farmers' age, the level of farming experience, and the longer the duration of GAP implementation are related to GAP adoption. 
Table 1. Descriptive statistics and comparison of characteristics between adopter groups.

\begin{tabular}{|c|c|c|c|c|c|c|c|c|}
\hline & \multirow[b]{2}{*}{ Demographic Characteristics } & \multicolumn{2}{|c|}{$\begin{array}{l}\text { New-Adopters } \\
(\mathrm{n}=104) 20.5 \%\end{array}$} & \multicolumn{2}{|c|}{$\begin{array}{l}\text { Mid-Adopters } \\
(\mathrm{n}=184) 36.2 \%\end{array}$} & \multicolumn{2}{|c|}{$\begin{array}{l}\text { Old-Adopters } \\
(\mathrm{n}=220) 43.3 \%\end{array}$} & \multirow[b]{2}{*}{$p$-Value } \\
\hline & & $\begin{array}{c}\text { Mean/ } \\
\text { Frequency }\end{array}$ & $\begin{array}{l}(\mathrm{SD}) / \\
\%\end{array}$ & $\begin{array}{c}\text { Mean/ } \\
\text { Frequency }\end{array}$ & $\begin{array}{l}(\mathrm{SD}) / \\
\%\end{array}$ & $\begin{array}{c}\text { Mean/ } \\
\text { Frequency }\end{array}$ & $\begin{array}{c}(\mathrm{SD}) / \\
\%\end{array}$ & \\
\hline & Gender $(\%)$ & & & & & & & 0.699 \\
\hline & Male & 54 & $51.9 \%$ & 86 & $46.7 \%$ & 107 & $48.6 \%$ & \\
\hline & Female & 50 & $48.1 \%$ & 98 & $53.3 \%$ & 113 & $51.4 \%$ & \\
\hline & Age (years) & 39.65 & $(10.98)$ & 44.60 & $(9.91)$ & 53.07 & $(9.82)$ & $0.000 * * *$ \\
\hline & Education & & & & & & & 0.312 \\
\hline a. & Lower-Secondary school & 60 & $57.69 \%$ & 117 & $63.59 \%$ & 121 & $55 \%$ & \\
\hline b. & Bachelor/diploma degree & 32 & $30.77 \%$ & 54 & $29.35 \%$ & 81 & $36.82 \%$ & \\
\hline c. & Higher than bachelor's degree & 12 & $11.54 \%$ & 13 & $7.06 \%$ & 18 & $8.18 \%$ & \\
\hline & Experience (years) & 18.47 & $(8.84)$ & 21.66 & $(8.40)$ & 27.72 & $(9.78)$ & $0.000^{* * *}$ \\
\hline
\end{tabular}

Notes: The ANOVA and compare mean methods were used to test the significant differences for interval variables: age and experience; whereas Pearson Chi-square tests were used to test the significant differences for categorical variables: gender and education. ${ }^{* * *}$ denote statistical significance at $p<0.001$.

\subsection{Comparison of Farmers' Perceptions and Attitudes Related to GAP}

The farmers' perceptions and attitudes regarding GAP practice were analyzed using the WAI. Results regarding perception and attitude were reported based on frequencies. The testing of the internal consistency of scales and the reliability of the perception and attitude responses was conducted using Cronbach's Alpha ( $\alpha$ ) approach [30]. The values of 0.813 for perception and 0.785 for attitude sections suggested that the items have relatively high internal consistency [31].

\subsubsection{Farmers' Perceptions of GAP}

Table 2 shows the level of the farmers' perceptions of GAP. All the respondents comprehended and agreed with the GAP regulation and compliance. Farmer's perceptions of the importance and benefit of GAP compliance were classified into five main categories: water quality, feed, farm management, harvesting, and animal health and welfare. Regarding water quality control, the WAI revealed that most of the farmers agreed on good water quality management and record-keeping as important processes in evaluating and improving performance within a farm operation.

There were some good agreements and compliance with the monitoring of important events, namely, checking water quality regularly, as well as constantly checking and repairing leaking ponds to prevent cross-contamination with exotic species. Keeping accurate farm records can identify problems in farm operations and be helpful in planning improvements for the next lot of production. Muddassir et al. [29] also emphasized maintenance of better water quality in aquaculture for safer production and better yield. The vast majority of farmers agreed that wastewater needs to be treated before released outside the farm. In Thailand, wastewater quality is subject to mandatory standards, and all farmers had complied with minimum legal requirements. The results of the F-test suggest that there is a significant difference between adopter groups in the perception regarding repairing leaking ponds $(p<0.05)$, wastewater treatment $(p<0.01)$, and recordkeeping $(p<0.01)$. Conversely, there were no statistical differences in other measures of water quality. This finding indicates that there is a difference between the farmer groups, especially mid-adopter farmers, who may give higher priority to record-keeping of water quality within the farm and cross-contamination from leaking ponds. Moreover, these groups also place more emphasis on wastewater treatment. 
Regarding feeding, the results of WAI show that all adopters agreed with guidelines for feed storage and handling. The farmers used shrimp feed from certified feed millers or prepared shrimp feed themselves from legally allowable ingredients. All the respondents agreed that veterinary drugs, chemicals, and probiotics prohibited by law should not be used, or, if used, should be registered with the relevant authority. The highest WAI score was noted in the mid-adopter's group, with a particular emphasis on having storage places for sanitation, including practices preventing cross-contamination and legally allowable ingredients, which are advantageous for shrimp growth. Wambua [32] revealed that poor feed management practices or low feed quality could result in low productivity. Adopter perceptions of these issues were significantly different when assessed by F-test with regards to feeding $(p<0.01)$, feed registration $(p<0.01)$, and using legally prohibited ingredients $(p<0.05)$. Conversely, there were no statistical differences noted relating to feed storage conditions.

In considering farm management, all adopters agreed to and complied with the GAP standard that farms should be registered with the DOF, in addition to local land use permits. Moreover, all farmers agreed with the concept of maintaining appropriate stocking density of shrimp larvae, since this can impact upon shrimp quality. Consistent with previous studies, it was understood that rearing shrimp at high stocking densities can increase waste accumulation and causes low shrimp growth [33]. However, there were no statistical differences in farm management practices among groups of adopters when assessed by F-test.

With regards to harvesting, all farmers strongly agreed with the GAP standard. Before the GAP adoption, farmers commonly used antibiotics and other chemicals in shrimp farming to prevent and treat disease outbreaks and control the pests. At present, in Thailand, legislation governing GAP states that farmers must not use any prohibited chemicals, unless under the authorization and supervision of veterinary professionals. Where such drug/chemical use is deemed necessary, there should be a withdrawal period prior to harvesting. Although there is no statistical difference in the perception regarding harvesting among groups, old-adopters strongly agreed that prohibited chemicals should only be used, where necessary, in compliance with relevant laws and regulations. Newadopters were the most likely to agree that in the chemical withdrawal period, veterinary supervision should be obtained. The occasional need for antibiotics and other drugs for pest control is an important issue that farmers felt should be addressed by the government. The results of this study are similar to Muddassir et al. [29] and Holmström et al. [34], who reported that all farmers were aware of the prohibited nature of chemicals. In terms of animal health and welfare management, all adopters strongly agreed with GAP standards. Mid-adopters particularly emphasized the need of GAP implementation in terms of disease control and prevention, while old-adopters were more likely to agree that outbreaks needed to be reported accurately and rapidly, to identify causes and avert the spread of the outbreak. Farmers reported concern about the impact of disease outbreaks because of all farmers; particularly older adopters had experienced massive production losses due to disease outbreaks caused by Early Mortality Syndrome (EMS) among shrimp. Similarly, Muddassir et al. [29] also reported that diseases were the major constraining determinant on productivity.

The relationship between farmers' perception on GAP adoption was assessed in five major domains, including water quality, feed, farm management, harvesting, and animal health and welfare. In terms of water quality, feed, farm management, and harvesting, all farmers agreed on GAP adoption. However, the differences in perception levels among groups were still observed in some specific dimensions, i.e., repairing pond, wastewater treatment, and record-keeping. Levels of perception were found to be varied for all feed dimensions except those related to feed storage conditions. WAI scores of animal health and welfare perspective again showed that farmers strongly agreed with all dimensions, yet the significant differences of perception levels were showed in the dimension related to animal welfare management and monitoring shrimp health. It can be concluded that 
farmers did agree with all domains of GAP standard, although levels of agreement varied by age and experience level.

Table 2. Farmers' perception on the GAP standards compliance.

\begin{tabular}{|c|c|c|c|c|}
\hline Perception & New-Adopters & Mid-Adopters & Old-Adopters & \\
\hline & WAI & WAI & WAI & $p$-Value \\
\hline \multicolumn{5}{|c|}{ Water Quality } \\
\hline Preventing the exotic species & 0.76 & 0.76 & 0.72 & 0.195 \\
\hline Checking water quality & 0.68 & 0.69 & 0.64 & 0.294 \\
\hline Farm facilities & 0.65 & 0.64 & 0.63 & 0.903 \\
\hline Complied with relevant laws & 0.60 & 0.63 & 0.58 & 0.413 \\
\hline Repairing pond & 0.68 & 0.70 & 0.64 & $0.047 *$ \\
\hline Water contamination & 0.73 & 0.74 & 0.69 & 0.111 \\
\hline Wastewater treatment & 0.72 & 0.76 & 0.68 & $0.005^{* *}$ \\
\hline Record-keeping & 0.77 & 0.79 & 0.70 & $0.003^{* *}$ \\
\hline \multicolumn{5}{|c|}{ Feed } \\
\hline Feeding & 0.67 & 0.74 & 0.69 & $0.006^{* *}$ \\
\hline Feed registration & 0.73 & 0.79 & 0.74 & $0.005^{* *}$ \\
\hline Do not use legally prohibited ingredients & 0.75 & 0.80 & 0.78 & $0.047 *$ \\
\hline Feed storage condition & 0.74 & 0.78 & 0.76 & 0.317 \\
\hline \multicolumn{5}{|c|}{ Farm Management } \\
\hline Stock density & 0.76 & 0.77 & 0.76 & 0.818 \\
\hline Farm registration & 0.79 & 0.80 & 0.78 & 0.677 \\
\hline \multicolumn{5}{|c|}{ Harvesting } \\
\hline Prohibited chemicals control & 0.76 & 0.79 & 0.81 & 0.131 \\
\hline Complied with relevant laws & 0.77 & 0.78 & 0.81 & 0.365 \\
\hline Certified buyer & 0.75 & 0.76 & 0.80 & 0.066 \\
\hline Preventing contamination & 0.74 & 0.75 & 0.77 & 0.477 \\
\hline Pet control & 0.79 & 0.76 & 0.79 & 0.161 \\
\hline $\begin{array}{l}\text { Using veterinary drugs under } \\
\text { veterinarian's supervision }\end{array}$ & 0.82 & 0.78 & 0.80 & 0.552 \\
\hline Keeping equipment & 0.69 & 0.72 & 0.73 & 0.423 \\
\hline \multicolumn{5}{|c|}{ Animal Health and Welfare } \\
\hline Animal welfare management & 0.77 & 0.82 & 0.78 & $0.036 *$ \\
\hline Informing disease outbreak & 0.83 & 0.83 & 0.84 & 0.973 \\
\hline Monitoring shrimp health & 0.77 & 0.80 & 0.75 & $0.043 *$ \\
\hline Causation analysis and corrective actions & 0.81 & 0.82 & 0.78 & 0.075 \\
\hline Disease control and prevention & 0.82 & 0.84 & 0.81 & 0.309 \\
\hline
\end{tabular}

Interpretation: The level of below 0.21 are considered as (strongly disagree), $0.21-0.4$ as (disagree), $0.41-0.6$ as (undecided), $0.61-0.8$ as (agree), $0.81-1$ as (strongly agree). Note: ${ }^{* *}{ }^{*}$ denote statistical significance at $p<0.01$ and $p<0.05$. Perception statements used in the survey. (Cronbach $\alpha=0.813$ ).

\subsubsection{Farmers' Attitude towards GAP}

Table 3 shows the farmers' attitudes towards the effective implementation of the GAP. Generally, farmers reported a highly positive attitude towards the performance of GAP standards. All respondents were satisfied with the results obtained by farming with GAP practices. Regarding environmental effects, the WAI score showed that all adopters agreed with the environmental protection effect of GAP practice. In particular, new-adopters strongly agreed with decreased chemical use. Furthermore, they agreed that GAP practices were environmentally-friendly and enhanced the effective use of resources. The result of the F-test suggests that there was a significant difference between adopter groups for these metrics $(p<0.001)$. The study shows that all adopter groups are interested in taking care of the environment, particularly new-adopters who showed much greater interest and responsibility than their older counterparts. The responses also suggest that all adopters are 
willing to reduce the use of the chemicals. This indicates that farmers are concerned about the environment and wish to take measures to ensure its protection. Similar results were obtained by Muddassir et al. [29], who reported that farmers showed a good understanding on the potential problems associated with the use of chemicals. In terms of constraints to the implementation of GAP practices, the significant differences of opinions were found among three adopter groups in all issues assessed $(p<0.001)$. WAI scores showed that although most of the farmers agreed with the GAP practices, implementation was restricted by issues such as high feed costs, especially for the mid-adopters. They noted that the registered feed from the certified feed millers was costly, and this was a major constraint for the small-scale farmers. Moreover, although over half of all adopters $(58.66 \%)$ had not completed secondary school, especially old-adopters $(23.82 \%)$, it is not an important issue for them because they also had the highest experience in farming. For all adopters, there is insufficient quality of seed and broodstocks due to inadequate GAP-certified hatcheries which are not enough for the farmers' needs. Looking at profit orientation, all adopters perceived that there was increased profit associated with GAP. There was no statistical difference in the levels of attitudes among the groups when assessed by F-test. Newadopters, in particular, believed that GAP practices were able to reduce production costs and increased farm income by conveying a price premium for the products.

The farmers further mentioned that GAP products had positive effects on their health and consumer's consumption patterns. They expected that buyers would be willing to pay more for GAP products. This is consistent with findings by Gerrard et al. [35], who found consumers were willing to pay a high price for the quality and certified products. In reality, at the local Thai market, the price paid for GAP products is still an obstacle for farmers as consumers mainly look for low-price products. In addition, one further goal of farmers was to become more productive so that their incomes might rise. Once farmers implement GAP practices and see their incomes rise, they will be more interested in continuing to use GAP farming techniques. Similarly, Flaten et al. [21] also reported the higher profit-motivated conversion of adopters. In terms of information, all adopters agreed with a need for knowledge about GAP. There is no statistical difference in the levels of attitudes among the groups when assessed by F-test. Old-adopters expressed particular interest in attending seminars/training to exchange knowledge with each other. Also, both new-adopters and old-adopters believed that GAP products and certified farms would be more likely to be accepted by the buyers and related parties. This confirms the belief that where training and networking are offered, farmers are much more likely to adopt GAP and have a positive attitude towards its implementation [24]. Regarding risk, all adopters perceived risk from GAP products and practices. There is no statistical difference in the levels of attitudes among the groups. New-adopters tend to pay close attention to fluctuations in price due to the GAP certification (which guarantees the production process but not an increase in sale price). Retailers and consumers are important drivers in price fluctuations in the market, and they expect quality products from certified farms. This is consistent with findings by Spadoni et al. [8] that European shopkeepers require their suppliers to show food safety certificates. Moreover, new-adopters and mid- adopters also pay close attention to the high cost of capital, especially new-adopters, who lack the initial capital needed to enter the GAP standard and improve their knowledge and farming skills. Furthermore, this lack of financial certainty has been cited as a leading reason why small-scale farmers have not yet participated widely in implementing GAP.

The farmers' attitudes on GAP adoption were assessed in five domains, namely environmental, constraint, profit orientation, information gathering, and risk. The farmers agreed with all dimensions of each domain, although the levels of attitudes differed by adoption groups in some dimensions of the environment and constraint domains. Interestingly, there is a significant difference in attitudes regarding constraints of GAP adoption were found in all evaluated dimensions, i.e., high feed cost, lack of good quality broodstock, and lack of GAP knowledge. Mid-adopters seem to be the group with the lowest constraint perceived. For the environmental domains, three dimensions with significantly different 
levels of attitudes were noted, i.e., efficient resource use, environmental impact, and chemical reduction. Among GAP adopters, new-adopter seems to have a higher positive attitude towards environmental factors. This might be the reason that new-adopters have implemented GAP standards on their farms. As mid- and older-adopters have implemented the standard for a while, these concerns may have become less important to them.

Table 3. Farmers' attitude on the GAP standards.

\begin{tabular}{|c|c|c|c|c|}
\hline Attitude & New-Adopters & Mid-Adopters & Old-Adopters & $p$-Value \\
\hline & WAI & WAI & WAI & \\
\hline \multicolumn{5}{|c|}{ Environmental } \\
\hline Using resources efficiently & 0.76 & 0.72 & 0.73 & $0.023 *$ \\
\hline Environmentally friendly & 0.80 & 0.77 & 0.77 & $0.000^{* * *}$ \\
\hline Reduce chemical use & 0.83 & 0.74 & 0.76 & $0.000 * * *$ \\
\hline Nature conservation & 0.76 & 0.72 & 0.73 & 0.161 \\
\hline Reduce waste & 0.78 & 0.74 & 0.76 & 0.227 \\
\hline \multicolumn{5}{|c|}{ Constraint } \\
\hline High feed cost & 0.68 & 0.54 & 0.61 & $0.000^{* * *}$ \\
\hline Lack of good quality seeds, brood stock & 0.72 & 0.63 & 0.66 & $0.001^{* * *}$ \\
\hline Lack of GAP knowledge & 0.68 & 0.54 & 0.61 & $0.000^{* * *}$ \\
\hline \multicolumn{5}{|c|}{ Profit } \\
\hline Reduce production costs & 0.66 & 0.65 & 0.66 & 0.921 \\
\hline Making more sales & 0.66 & 0.64 & 0.65 & 0.851 \\
\hline Higher price premium & 0.74 & 0.71 & 0.73 & 0.537 \\
\hline Increasing products quality & 0.73 & 0.71 & 0.73 & 0.633 \\
\hline Increasing productivity & 0.74 & 0.70 & 0.73 & 0.363 \\
\hline \multicolumn{5}{|c|}{ Information Gathering } \\
\hline Accepted by related-parties & 0.69 & 0.70 & 0.70 & 0.889 \\
\hline Generate a connection network between communities & 0.74 & 0.73 & 0.73 & 0.885 \\
\hline Participation in related organizations & 0.75 & 0.74 & 0.73 & 0.855 \\
\hline Attending/training on GAP & 0.75 & 0.72 & 0.76 & 0.268 \\
\hline \multicolumn{5}{|c|}{ Risk } \\
\hline Price fluctuation & 0.66 & 0.65 & 0.64 & 0.742 \\
\hline Lack of GAP practices & 0.68 & 0.65 & 0.64 & 0.382 \\
\hline High capital cost & 0.68 & 0.65 & 0.63 & 0.286 \\
\hline
\end{tabular}

Interpretation: The level of below 0.21 are considered as (strongly disagree), $0.21-0.4$ as (disagree), $0.41-0.6$ as (undecided), $0.61-0.8$ as (agree), $0.81-1$ as (strongly agree). Note: ${ }^{* * *},{ }^{*}$ denote statistical significance at $p<0.001$ and $p<0.05$. Attitudinal statements used in the survey. (Cronbach $\alpha=0.785$ ).

\section{Conclusions and Recommendations}

This study mainly investigated the farmers' perspectives on GAP adoption in Thailand. The demographic differences of GAP certified farmers were identified and the relationship of farmers' perceptions and attitudes on the GAP adoption was assessed. The differences among the adopter groups provides new information into the GAP adoption. For each domain assessed, all adopters agree with the GAP's principles, especially in increasing product quality and productivity. In addition, the majority of the respondents agreed with the GAP as a sustainable and efficient production system, particularly in matters of environmental conservation. Furthermore, the majority of the respondents also agreed with the use any chemical substances strictly for the GAP provisions, following the regulations and relevant experts. However, farmers were less aware about the antimicrobial and other veterinary drugs residues contaminating the aquatic products.

There is no variation in actual price of shrimp whether produced under GAP or nonGAP farms. Thus, most of the farmers, especially small and medium enterprises (SMEs) have less motivation for enrollment in GAP certification. Moreover, in terms of animal 
health and welfare, farmers emphasize disease breakout control and prevention including notification of an outbreak as soon as possible. The evidence from this survey indicate that farm owners still have some misconceptions on the GAP which influence the adoption of measures. More education regarding the use of chemicals and effects of foodborne diseases may influence the farmers' attitude towards safer production and enhance the adoption of the accurate measures. Based on the WAI score, the differences in the regularity of practices were obviously seen between GAP adopter and non-adopter groups.

The findings would help policy-makers to build the capacity of shrimp farmers or take action appropriately. Enhanced farmer education and preparation are required. Thus, public relations should be used, and training to transfer GAP knowledge for farmers should be organized. Nevertheless, content, language, and presentation methods for farmers education need to be easy to understand. Furthermore, incentive measures may help to reduce farmer constraints to GAP adoption. Here, the government may assist by generating and supporting a market tool to create price variance between GAP products and non-GAP products, including encouraging consumers to buy GAP products at a reasonable price, thus ensuring farmer reward for improved standards. Another approach to help farmers to engage in the GAP system is to search for collaboration from lending sources. The appropriate loan requirements and low-interest rates should be set to encourage standard adoption. This will help alleviate some of the cost constraints that were identified as crucial issues in this research.

Author Contributions: Conceptualization, C.B. and A.K.A.; methodology, C.B.; formal analysis, C.B. and A.K.A.; writing-original draft preparation, C.B. and A.K.A.; writing-review and editing, A.K.A.; supervision, A.K.A. All authors have read and agreed to the published version of the manuscript.

Funding: This research received no external funding.

Institutional Review Board Statement: Not applicable.

Informed Consent Statement: Not applicable.

Data Availability Statement: Data within the article.

Acknowledgments: The authors would like to express a great appreciation to the Ministry of Agricultural and Cooperatives, Thailand, for the scholarship to the first author to pursue a Doctoral degree at the Asian Institute of Technology, Thailand.

Conflicts of Interest: The authors declare no conflict of interest.

\section{References}

1. Meixner, O.; Katt, F. Assessing the Impact of COVID-19 on Consumer Food Safety Perceptions-A Choice-Based Willingness to Pay Study. Sustainability 2020, 12, 7270. [CrossRef]

2. Kurina, B.; Wayne, G.; Lendel, N.; Baksh, K.; Ganpat, W.; Narine, L. Farmers knowledge, attitudes and perceptions of occupational health and safety hazards in Trinidad, West Indies and implications for the Agriculture sector. J. Agric. Ext. Rural. Dev. 2015, 7, 221-228. [CrossRef]

3. Thapa, S.P.; Shrestha, S.; Anal, A.K. Addressing the antibiotic resistance and improving the food safety in food supply chain (farm-to-fork) in Southeast Asia. Food Control. 2020, 108, 106809. [CrossRef]

4. Corsin, F.; Funge-Smith, S.; Clausen, J. A Qualitative Assessment of Standards and Certification Schemes Applicable to Aquaculture in the Asia-Pacific Region. 2007. Available online: http://www.fao.org/3/a-ai388e.pdf (accessed on 3 September 2018).

5. Anal, A.K.; Perpetuini, G.; Petchkongkaew, A.; Tan, R.; Avallone, S.; Tofalo, R.; Van Nguyen, H.; Chu-Ky, S.; Ho, P.H.; Phan, T.T.; et al. Food safety risks in traditional fermented food from South-East Asia. Food Control. 2020, 109, 106922. [CrossRef]

6. Liu, P.; Casey, S.; Cadilhon, J.; Hoejskov, P.; Morgan, N.; A Practical Manual for Producers and Exporters from Asia. Regulations, Standards and Certification for Agricultural Exports. RAP Publication (FAO). 2007. Available online: http://www.fao.org/3/aag130e.pdf (accessed on 12 July 2020).

7. Wongprawmas, R.; Canavari, M.; Waisarayutt, C. A multi-stakeholder perspective on the adoption of good agricultural practices in the Thai fresh produce industry. Br. Food J. 2015, 117, 2234-2249. [CrossRef]

8. Spadoni, R.; Lombardi, P.; Canavari, M.; Hingley, M. Private food standard certification: Analysis of the BRC standard in Italian agri-food. Br. Food J. 2014, 116, 142-164. [CrossRef] 
9. Rezaei, R.; Mianaji, S.; Ganjloo, A. Factors affecting farmers' intention to engage in on-farm food safety practices in Iran: Extending the theory of planned behavior. J. Rural. Stud. 2018, 60, 152-166. [CrossRef]

10. Young, I.; Rajić, A.; Hendrick, S.; Parker, S.; Sánchez, J.; McClure, J.; McEwen, S. Attitudes towards the Canadian quality milk program and use of good production practices among Canadian dairy producers. Prev. Veter. Med. 2010, 94, 43-53. [CrossRef]

11. Zhong, Y.; Huang, Z.; Wu, L. Analysis on the factors influencing the safety production behaviour of pig farmers. Chin. J. Anim. Sci. 2016, 20, 1-5.

12. Ravuru, J.N.M.A.D.B. Growth of Cultured White Leg Shrimp Litopenaeus Vannamei (Boone, 1931) of Brackish Water Culture System in Winter Season with Artificial Diet. J. Aquac. Res. Dev. 2015, 06, 2. [CrossRef]

13. Department of Fisheries (DOF), Situation of marine shrimp products in 2018. Fisheries Development Policy and Strategy Division. 2018. Available online: http://thacert.fisheries.go.th/wscert/site/certificate_list.jsp (accessed on 15 September 2020).

14. Srisopaporn, S.; Jourdain, D.; Perret, S.R.; Shivakoti, G. Adoption and continued participation in a public Good Agricultural Practices program: The case of rice farmers in the Central Plains of Thailand. Technol. Forecast. Soc. Chang. 2015, 96, $242-253$. [CrossRef]

15. Trienekens, J.; Zuurbier, P. Quality and safety standards in the food industry, developments and challenges. Int. J. Prod. Econ. 2008, 113, 107-122. [CrossRef]

16. Tookwinas, S.; Chiyakum, K.; Somsueb, S. Aquaculture of White Shrimp Penaeus Vannamei in Thailand. 2005. Available online: https: / / repository.seafdec.org.ph/handle/10862/855 (accessed on 14 October 2020).

17. Department of Fisheries (DOF), Database of Aquaculture Farm Certification Standards. Fisheries Commodity Standard Sys-tem and Traceability Division. 2019. Available online: http:/ / thacert.fisheries.go.th/wscert/site/certificate_list.jsp (accessed on 15 October 2020).

18. Thongpalad, K.; Kuwornu, J.K.; Datta, A.; Chulakasian, S.; Anal, A.K. On-farm food safety knowledge, attitudes and self-reported practices of layer hen farmers. Br. Food J. 2019, 121, 1912-1925. [CrossRef]

19. Bixley, B.; Yamane, T. Statistics: An Introductory Analysis. Can. J. Econ. Politi- Sci. 1965, 31, 163. [CrossRef]

20. Läpple, D.; Van Rensburg, T. Adoption of organic farming: Are there differences between early and late adoption? Ecol. Econ. 2011, 70, 1406-1414. [CrossRef]

21. Flaten, O.; Lien, G.; Ebbesvik, M.; Koesling, M.; Valle, P.S. Do the new organic producers differ from the 'old guard'? Empirical results from Norwegian dairy farming. Renew. Agric. Food Syst. 2006, 21, 174-182. [CrossRef]

22. Paul, S.K.; Hossain, M.N. People's perception about flood disaster management in Bangladesh: A case study on the Chalan Beel Area. Stamford J. Environ. Hum. Habitat 2013, 2, 72-86.

23. Ndamani, F.; Watanabe, T. Farmers' Perceptions about Adaptation Practices to Climate Change and Barriers to Adaptation: A Micro-Level Study in Ghana. Water 2015, 7, 4593-4604. [CrossRef]

24. Van Bac, H.; Nanseki, T.; Chomei, Y. Factors influencing tea farmers decision to adopt Vietnamese good agricultural practices in Northern Vietnam. J. Agric. Econ. Dev. 2017, 6, 12-19.

25. Ngokkuen, C.; Grote, U. Geographical indication for jasmine rice: Applying a logit model to predict adoption behavior of Thai farm households. Q. J. Int. Agric. 2012, 51, 157-185. [CrossRef]

26. Nkamleu, G.B.; Manyong, V.M. Factors affecting the adoption of agroforestry practices by farmers in Cameroon. Small-Scale For. Econ. Manag. Policy 2005, 4, 135-148. [CrossRef]

27. Ruben, R.; Fort, R. The Impact of Fair-Trade Certification for Coffee Farmers in Peru. World Dev. 2012, 40, 570-582. [CrossRef]

28. Kersting, S.; Wollni, M. New institutional arrangements and standard adoption: Evidence from small-scale fruit and vegetable farmers in Thailand. Food Policy 2012, 37, 452-462. [CrossRef]

29. Muddassir, M.; Noor, M.A.; Ahmed, A.; Aldosari, F.; Waqas, M.A.; Zia, M.A.; Mubushar, M.; Zuhaibe, A.-U.-H.; Jalip, M.W. Awareness and adoption level of fish farmers regarding recommended fish farming practices in Hafizabad, Pakistan. J. Saudi Soc. Agric. Sci. 2019, 18, 41-48. [CrossRef]

30. Cronbach, L.J. Coefficient alpha and the internal structure of tests. Psychometrika 1951, 16, 297-334. [CrossRef]

31. Tavakol, M.; Dennick, R. Making sense of Cronbach's alpha. Int. J. Med. Educ. 2011, 2, 53-55. [CrossRef]

32. Wambua, M. A Cost Benefit Analysis of the Fish Farming Enterprise and Productivity Program in Kenya. 2018. Available online: https:/ / www.grocentre.is/static/gro/publication/351/document/moses15prf.pdf (accessed on 10 July 2020).

33. Tan, J.; Luan, S.; Cao, B.; Luo, K.; Meng, X.; Kong, J. Comparison of growth and reproduction performance of broodstock Pacific white shrimp Litopenaeus vannamei reared in oceanic and brackish water. Aquac. Res. 2019, 50, 1893-1902. [CrossRef]

34. Holmstrom, K.; Graslund, S.; Wahlstrom, A.; Poungshompoo, S.; Bengtsson, B.-E.; Kautsky, N. Antibiotic use in shrimp farming and implications for environmental impacts and human health. Int. J. Food Sci. Technol. 2003, 38, 255-266. [CrossRef]

35. Gerrard, C.; Janssen, M.; Smith, L.; Hamm, U.; Padel, S. UK consumer reactions to organic certification logos. Br. Food J. 2013, 115, 727-742. [CrossRef] 